Bảng 7. Tình trạng thể mi trên UBM

\begin{tabular}{|c|c|c|c|c|c|}
\hline $\begin{array}{c}\text { Tình } \\
\text { trạng } \\
\text { thể mi }\end{array}$ & $\begin{array}{c}\text { Bình } \\
\text { thường }\end{array}$ & $\begin{array}{c}\text { Deet vàt và } \\
\text { xoay } \\
\text { trước }\end{array}$ & $\begin{array}{c}\text { Xoay } \\
\text { trước }\end{array}$ & Dẹt & Tổng \\
\hline $\begin{array}{c}\text { Số lượng } \\
(\%)\end{array}$ & $\begin{array}{c}1 \\
(1,9 \%)\end{array}$ & $\begin{array}{c}34 \\
(64,2 \%)\end{array}$ & $\begin{array}{c}11 \\
(20,8 \%)\end{array}$ & $\begin{array}{c}7 \\
(13,2 \%)\end{array}$ & 53 \\
\hline
\end{tabular}

\section{KẾT LUÂN}

Người bệnh glôcôm ác tính thường vào viện trong tình trạng mắt bệnh nặng, với TL kém (dưới 20/400), NA trung bình rất cao (34 $\mathrm{mmHg}$ ), tiền phòng rất nông hoặc xẹp (độ sâu TP trung bình $0,7 \mathrm{~mm}$ ). Bệnh cảnh lâm sàng nă̆ng nề trên là hậu quả của tình trạng xẹp TP kết hợp với NA cao gây phù GM ở các mức độ khác nhau. Glôcôm ác tính thường gặp trên người bệnh lớn tuổi, nữ giới. Các đặc điểm thuận lợi gây bệnh bao gồm: một mắt đã bị glôcôm ác tính, phấu thuật cắt bè CGM trên mắt có hình thái góc tiền phòng đóng, TNC ngắn.

\section{TÀI LIỆ THAM KHẢO}

1. Spaeth GL and A. S, Comparison of the configuration of the human anterior chamber angle, as determined by the Spaeth gonioscopic grading system and ultrasound biomicroscopy. Trans Am Acad Ophthalmol Soc., 1995. 93: p. 337-347.

2. Trope GE. Malignant glaucoma: clinical and ultrasound biomicroscopic features. Ophthalmology, 1994. 101(6): p. 1030-1035.

3. Razeghinejad MR, Amini $H$, Esfandiari $H$. (2005). Lesser anterior chamber dimensions in women may be a predisposing factor for malignant glaucoma. Medical Hypotheses; 64:572-574.

4. Prata TS and Dorairaj. S. Is preoperative ciliary body and iris anatomical configuration a predictor of malignant glaucoma development? Clin Experiment Ophthalmol, 2013. 41(6): p. 541-545.

5. Epstein DL and Hashimoto JM. Experimental perfusions through the anterior and vitreous chambers with possible relationships to malignant glaucoma. Am J Ophthalmology, 1979. 88: p. 1078-1086.

6. J C Tsai et al (1997). Surgical results in malignant glaucoma refractory to medical or laser therapy. Eye. 02/1997; 11 (Pt 5)(5):677-81.

7. Harbour JW., Rubsamen $\mathbf{P E}$, Palmberg $\mathbf{P}$ (1996). Pars plana vitrectomy in the management of phakic and pseudophakic malignant glaucoma. Arch Ophthalmol; 114:1073-1078.

8. Zhou et al (2012). Clinical Analysis of 50 Chinese Patients with Aqueous Misdirection Syndrome: a Retrospective Hospital-based Study.J Int Med Res,40(4):1568-79.

\title{
TÌNH HÌNH THỂ LỰC, BÊNNH TÂT VÀ MộT Số YẾU TỐ LIÊN QUAN ĐẾN SỨC KHỎE NAM THANH NIÊN THỰC HIỆN NGHĨA VỤ QUÂN SỰ TỈNH CÀ MAU NĂM 2020
}

\section{TÓM TẮT}

Đặt vấn đề: Theo thống kê báo cáo của các Hội đồng Nghĩa vu quân sư trong tỉnh Cà Mau, những năm gân đây tỷ lệ thanh niên trong độ tuổi thực hiện nghĩa vụ quân sự (NVQS) có sức khỏe tốt chiếm tỷ lệ thấp, sức khỏe kém chiếm tỷ lệ cao. Muc tiêu nghiên cứu: 1 . Xác định tỷ lệ các nhóm sức khỏe, thể lực và bênh tật của nam thanh niên trong độ tuối thực hiện nghĩa vụ quân sự. 2. Khảo sát một số yếu tố liên quan đến tình trang thể lực và bênh tật của nam than niên trong độ tuổi thức hiện nghĩa vụ quân sự tại tỉnh Cà Mau năm 2020. Đối tượng và Phương pháp nghiên cứu: Nghiên cứu mô tả cắt ngang có phân tích trên 814 nam thanh niên trong độ tuổi thực hiện NVQS bằng bộ câu hỏi soan sẵn. Xử lý số liệu bằng phần mềm SPSS 19.0. Kết quả nghiên cứu: Tỷ lệ sức khỏe loại 1 chiếm 2,1\%, loại 2 chiếm 9,2\%, loại 3

${ }^{1}$ Bênh viện Đa khoa tỉnh Cà Mau

${ }^{2}$ Trường Đai hoc Y Dước Cần Tho

Chịu trách nhiệm chính: Nguyễn Minh Phương

Email: nmphuong@ctump.edu.vn

Ngày nhận bài: 4.3.2021

Ngày phản biên khoa học: 20.4.2021

Ngày duyệt băi: 28.4.2021

\section{Trương Thị Yến Linh ${ }^{1}$, Nguyễn Minh Phương²}

chiếm $20,1 \%$, loai 4 chiếm 20,9\%, loại 5 chiếm $13,8 \%$, loai 6 chiếm 33,9\%. Nhóm sức khỏe tốt (loai $1,2,3$ ) chiểm $31,4 \%$, nhóm sức khỏe kém (loai $4,5,6$ ) chiếm $68,6 \%$. Tý lệ thể lực loại 1 chiếm $42,4 \%$, loại 2 chiếm $25,3 \%$, loai 3 chiếm $19,4 \%$, loai 4 chiếm $4,9 \%$, loai 5 chiếm 2,9\%, loại 6 chiếm $5 \%$. Tỷ lệ nam thanh niển không mắc bếnh nội khoa chiếm $36,2 \%$ và không mắc bênh ngoai khoa chiếm $87 \%$. Một số yếu tố liên quan đến tinh trạng sức khỏe kém của đối tượng nghiên cứu: tuổi $>20$, hoc vấn trên THPT, sống ở thành thị, có uống rượu bia. Kết luận: Tý lệ nam thanh niến có sức khỏe kém chiếm tỷ lệ khá cao. Cần quan tâm đến các yếu tố như độ tuổi, học vấn và sử dụng rượu bia để cải thiện tình trạng sức khỏe của thanh niển.

Tư khoá: thể lực, bệnh tật, thanh niên, nghĩa vụ quân sự, Cà Mau.

\section{SUMMARY}

\section{A STUDY OF PHYSICAL CONDITION, DISEASES AND SOME FACTORS RELATED \\ TO THE HEALTH OF MALE ADOLESCENTS PERFORMING MILITARY SERVICE IN CA MAU IN 2020}

Background: According to statistics reported by 
the Military Service Councils in Ca Mau province, in recent years, the proportion of young people in the military service age having good health was low and poor health was high. Objective: 1. Determining the prevalence of health group, physical condition and diseases of male adolescents. 2. Finding some factors related to the physical condition and diseases of adolescents in performing military service age in 2020 in Ca Mau province. Subjects and Method: A crosssectional descriptive study was conducted on 814 adolescents in performing military service age. All data was collected by questionaires. SPSS 19.0 software was used for analyzing data. Results: The rate of health grade 1 accounts for $2.1 \%$, grade 2 accounts for $9.2 \%$, grade 3 accounts for $20.1 \%$, grade 4 accounts for $20.9 \%$, grade 5 accounts for $13.8 \%$ and grade 6 accounts $33.9 \%$. The percentage of good health group (grade $1,2,3$ ) was $31,4 \%$ and poor health group (grade $4,5,6$ ) was $68,6 \%$. The number of adolescents had grade 1 physical condition was $42,4 \%, 25,3 \%$ of grade $2,19,4 \%$ of grade $3,4,9 \%$ of grade $4,2,9 \%$ of grade 5 and $5 \%$ of grade 6 . The percentage of young men who do not have internal medicine diseases accounts for $36.2 \%$ and do not have surgical diseases was $87 \%$. Some factors related to poor health of study subjects: age above 20, education level above high school, living in urban areas and drinking alcohol. Conclusion: The percentage of young men with poor health is quite high. It is needed to pay attention to factors related to poor health of them such as age, education and alcohol use to improve youth health.

Key words: physical condition, diseases, adolescents, military service, Ca Mau.

\section{I. ĐĂT VẤN ĐÊ}

Thanh niên là một lực lượng xã hội to lớn, một trong những nhân tố quan trọng quyết định tương lai, vận mệnh dân tộc. Điều kiện tiên quyêt để thanh niên làm tốt trọng trách của mình chính là sức khỏe. Theo thống kê báo cáo của các Hội đồng Nghĩa vụ quân sự trong tỉnh Cà Mau, những năm gần đây tỳ lệ thanh niên trong độ tuổi thực hiện nghĩa vụ quần sự có sức khỏe tốt chiếm tỷ lệ thấp, sức khỏe kém chiếm tỷ lệ cao [3]. Vì vậy, chúng tôi chọn đề tài: "Nghiên cứu tình hình thể lực, bệnh tật và một số yếu tố liên quan đến sức khỏe nam thanh niên thực hiện nghĩa vụ quân sự tỉnh Cà Mau năm 2020" với mục tiêu sau:

1. Xác định tỷ lệ các nhóm sức khỏe, thể lực và bệnh tật của nam thanh niên trong độ tuối thực hiện nghĩa vụ quân sự tại tỉnh Cà Mau năm 2020

2. Khảo sát một số yêu tố liên quan đến tình trạng thể lực và bệnh tật của nam thanh niên trong độ tuổi thực hiện nghĩa vụ quân sự không đủ sức khỏe tại tỉnh Cà Mau năm 2020.

\section{II. ĐỐI TƯợNG VÀ PHƯƠNG PHÁP NGHIÊN CỨU 2.1. Đối tượng nghiên cứu:}

Nghiên cứu được tiến hành trên nam thanh niên trong độ tuổi thực hiện NVQS tại tỉnh Cà Mau trong năm 2020.

- Tiêu chuẩn chọn mẫu: Nam thanh niên trong độ tuổi khám tuyển nghĩa vụ quân sự, có mặt tham gia khám sức khỏe NVQS năm 2020 tại Hội đồng khám sức khỏe NVQS các địa phương trong tỉnh Cà Mau.

- Tiêu chuẩn loại trừ: Những người không khám đầy đủ chuyên khoa, thiếu các chỉ số cần nghiên cứu. Không đồng ý tham gia nghiên cứu.

- Thời gian nghiên cứu: từ tháng 6 năm 2020 đến tháng 6 năm 2021.

\subsection{Phương pháp nghiên cứu}

Thiết kế nghiên cứu: Phương pháp nghiên cứu mô tả cắt ngang có phân tích.

\section{Cõ̃ mẫu:}

$$
\mathrm{n}=Z_{1-\alpha / 2}^{2} \frac{p(1-p)}{d^{2}}
$$

Trong đó: $\mathrm{n}$ : cõ mẫu nghiên cứu

a: xác suất sai lầm loại $I$, với $a=0,05$.

Z: trị số từ phân phối chuẩn, với độ tin cậy $95 \%$ thì $Z=1,96$.

p: là tỷ lệ nam thanh niên trong độ tuổi thực hiện NVQS không đủ sức khỏe tuyển vào quẩn đội (loại 4 - loại 6) [4] chọn $p=0,52$

d: sai số cho phép $(d=0,05)$.

Thay vào công thức ta được cõ̃ mẫu $\mathrm{n}=383$, hiệu lực thiết kế $=2$, được $n=383 \times 2=766$ thực tế ghi nhận 814.

Phương pháp chọn mẫu: Chọn mẫu nhiều giai đoan.

- Giai đoạn 1: Chọn mẫu ngẫu nhiên, bốc thăm chọn 3 huyện/thành phố tương đương số cõ̃ mẫu: Thành phố Cà Mau, huyện $U$ Minh và huyện Cái Nước.

- Giai đoạn 2: Chọn đối tượng nghiên cứu tại 3 huyện/thành phố theo phương pháp ngấu nhiên hệ thống.

Danh sách thanh niên được khám, phân loại sức khỏe NVQS lập tại các Hội đồng khám sức khỏe NVQS. Tính khoảng cách mẫu, chọn đối tượng cần điều tra có: $1.754 / 770=2,2$ làm tròn số khoảng cách mẫu $\approx 2$.

- Giai đoạn 3: Cộng tác viên trực tiếp gặp các đối tượng nghiên cứu trao đổi và phát phiếu phỏng vấn, thu thập thông tin đối tượng nghiên cứu tại các đợt khám sức khỏe NVQS tại các địa phương.

Nội dung nghiên cứu: Các chỉ tiêu về bệnh tật cho điểm đối với các bệnh thuộc chuyên khoa khác nhau trong đó có Nội khoa, Ngoại khoa; Các yếu tố liên quan đến sức khỏe kém (nhóm tuổi, trình độ văn hóa, nơi sinh sống, tình trạng 
kinh tế, hút thuốc, lạm dụng rượu, bia,...).

Phương pháp thu thập số liệu: bằng bộ câu hỏi phỏng vấn đã thiết kế sẵn.

Phân tích số liệu: Số liệu nghiên cứu được xử lý bằng phần mềm SPSS 19.0.

\section{KẾT QUẢ NGHIÊN CỨU}

3.1. Phân loại sức khỏe của đối tượng nghiên cứu

\subsubsection{Phân loại sức khỏe chung}

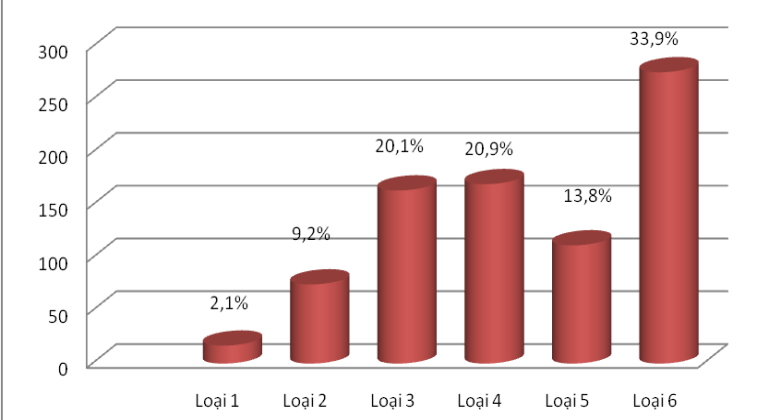

Biêu đồ 1. Tỷ lệ các loại sức khỏe của nam thanh niên trong độ tuôỉ thức hiện NVQS

Nhân xét: Sức khỏe của nam thanh niên trong độ tuổi thực hiện NVQS: loại 6 cao nhất chiếm 33,9\%; loại 4 chiếm 20,9\%; loại 3 chiếm 20,1\%.

3.2.2. Phân loại thể lực của nam thanh niên trong độ tuổi thực hiện nghĩa vụ quân sự tính theo chiêu cao, cân nặng và vòng ngực

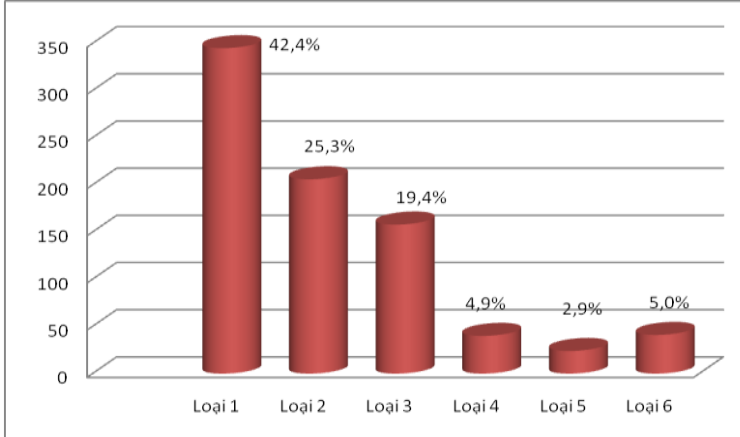

Biểu đồ 2. Tỷ lệ các loại thể lực theo chiêu cao, cân nặng và vòng ngực

3.3. Khảo sát một số yếu tố liên quan đến sức khỏe kém của thanh niên trong độ tuổi thực hiện nghĩa vụ quân sự tại tỉnh Cà Mau

Bảng 1. Liên quan giữa tình trạng sức khỏe và tuổi của đôî tượng nghiên cứu

\begin{tabular}{|c|c|c|c|c|c|c|}
\hline \multirow{2}{*}{ Tuổi } & \multicolumn{2}{|c|}{ Sức khỏe kém } & \multicolumn{2}{|c|}{ Sức khỏe tốt } & \multirow{2}{*}{$\begin{array}{c}\text { OR } \\
\text { KTC 95\% }\end{array}$} & \multirow{2}{*}{$\mathbf{P}$} \\
\hline & $\mathbf{n}$ & $\%$ & $\mathbf{n}$ & $\%$ & & \\
\hline$>20$ & 270 & 78,9 & 72 & 21,1 & \multirow{3}{*}{$\begin{array}{c}1,852 \\
(1,465-2,340)\end{array}$} & \multirow{3}{*}{0,0001} \\
\hline$\leq 20$ & 288 & 61 & 184 & 39 & & \\
\hline Tống & 558 & 68,6 & 256 & 31,4 & & \\
\hline
\end{tabular}

Nhân xét: Nam thanh niên trong độ tuối thực hiện NVQS có sức khỏe kém ở nhóm >20 tuổi cao 1,852 lần nhóm $\leq 20$ tuổi; tỷ lệ lần lượt là 78,9\% và $61 \%$. Khác biệt có ý nghĩa thống kê với $p<0,05$.
Nhận xét: Nam thanh niên trong độ tuổi thực hiện NVQS có thể lực loại 1 chiếm 42,4\%, loại 2 và 3 lân lượt là 25,3\% và 19,4\%.

3.2.3. Tỷ lệ các nhóm bệnh tật của của thanh niên trong độ tuổi thực hiện NVQS

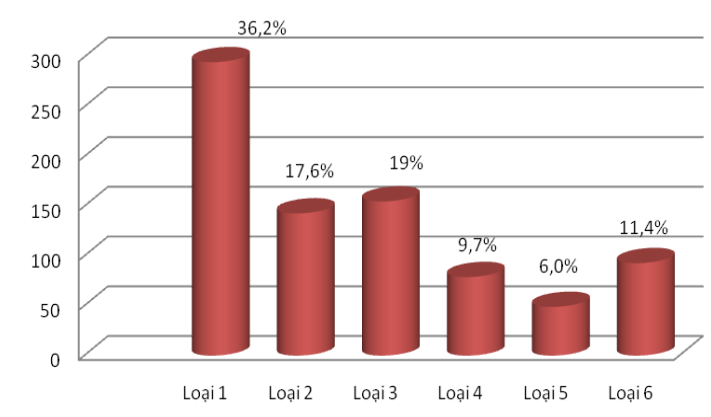

Biểu đổ 3. Tỷ lệ mức độ bệnh tật về nọi khoa

Nhân xét: Đối tượng thanh niên là lứa tuổi trẻ khỏe, kết quả trên có tỷ lệ không mắc bệnh nội khoa chiếm tỷ lệ thấp (nhóm 1 điểm 36,2\%), còn lại là có mắc bệnh tật nội khoa chiếm tỷ lệ cao 63,8\% (bao gôm nhóm 2, 3, 4, 5, 6 điểm, với tỷ lệ 17,6\%, 19\%, 9,7\%,6\%, 11,4\%).

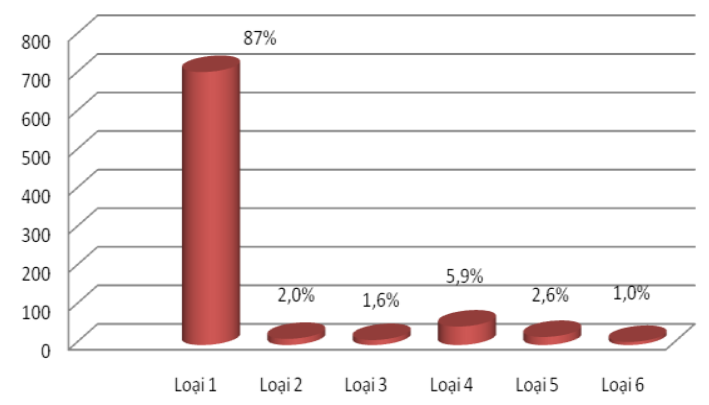

Biêu đồ 4. Tỷ lệ mức độ bệnh tật về ngoại khoa Nhận xét: Nhóm đạt 1 điểm (tức không bệnh tật) trong đánh giá về bệnh tật ngoại khoa của nam thanh niên trong độ tuổi thực hiện NVQS tại Cà Mau chiếm $87 \%$, các nhóm có bệnh tât chiếm tỷ lệ thấp 13\% (gồm nhóm 2,3,4,5,6 điểm với tỷ lệ $2 \%, 1,6 \%, 5,9 \%, 2,6 \%, 1 \%)$. 
Bảng 2: Liên quan giữa tình trạng sức khỏe với yêu tố trình độ học vấn của đôi tượng nghiên cứlu.

\begin{tabular}{|c|c|c|c|c|c|c|}
\hline \multirow{2}{*}{ Trình độ học vấn } & \multicolumn{2}{|c|}{ Sức khỏe kém } & \multicolumn{2}{|c|}{ Sức khỏe tốt } & \multirow{2}{*}{ Or } & \multirow{2}{*}{ P } \\
\cline { 2 - 5 } & $\mathbf{n}$ & $\mathbf{\%}$ & $\mathbf{n}$ & $\mathbf{9 5}$ & \\
\hline THCS trở xuống & 193 & 64,8 & 105 & 35,2 & \multirow{2}{*}{1,204} & \multirow{2}{*}{$\mathbf{0 , 0 4 6}$} \\
\hline THPT trở lên & 365 & 70,7 & 151 & 29,3 & $(0,982-1,477)$ & \\
\hline Tống & $\mathbf{5 5 8}$ & $\mathbf{6 8 , 6}$ & $\mathbf{2 5 6}$ & $\mathbf{3 1 , 4}$ & $(0,4)$ & \\
\hline
\end{tabular}

Nhân xét: Có mối liên quan với tỷ lê nam thanh niên sức khỏe kém thuộc nhóm trình độ THCS trở xuống chiếm $64,8 \%$ và THPT trở lên chiếm $70,7 \%$. Khác biệt có ý nghĩa thống kê với $p=0,046<0,05$. cứu.

Bảng 3: Liên quan giữa tình trạng sức khỏe với yêú tố nơi cư trú của đôi tượng nghiên

\begin{tabular}{|c|c|c|c|c|c|c|}
\hline \multirow{2}{*}{ Nơi cư trú } & \multicolumn{2}{|c|}{ Sức khỏe kém } & \multicolumn{2}{c|}{ Sức khỏe tốt } & \multirow{2}{*}{ OR } & \multirow{2}{*}{ KTC 95\% } \\
\cline { 2 - 5 } & $\mathbf{n}$ & $\mathbf{\%}$ & $\mathbf{n}$ & $\mathbf{\%}$ & \\
\hline Thành thị & 358 & 73,1 & 132 & 26,9 & \multirow{2}{*}{0,704} & \multirow{2}{*}{$\mathbf{0 0 0 0}$} \\
\hline Nông thôn & 200 & 61,7 & 124 & 38,3 & $(0,576-0,861)$ & \\
\hline Tống & $\mathbf{5 5 8}$ & $\mathbf{6 8 , 6}$ & $\mathbf{2 5 6}$ & $\mathbf{3 1 , 4}$ & \\
\hline
\end{tabular}

Nhận xét: Nam thanh niên có sức khỏe kém ở nhóm sinh sống ở thành thị cao hơn nhóm sinh sống ở nông thôn; tỷ lệ lần lượt là $73,1 \%$ và $61,7 \%$. Khác biệt có ý nghĩa thống kê với $\mathrm{p}=$ $0,000<0,05$.

Bảng 4. Liên quan giứa tình trạng sức khỏe với yếu tố lạm dụng rượu, bia của đôi tượng nghiên cứu.

\begin{tabular}{|c|c|c|c|c|c|c|}
\hline \multirow{2}{*}{ Uống rượu, bia } & \multicolumn{2}{|c|}{ Sức khỏe kém } & \multicolumn{2}{|c|}{ Sức khỏe tốt } & \multirow{2}{*}{$\begin{array}{c}\text { OR } \\
\text { KTC 95\% } \\
\end{array}$} & \multirow[b]{2}{*}{$\mathbf{p}$} \\
\hline & $\mathbf{n}$ & $\%$ & $\mathbf{n}$ & $\%$ & & \\
\hline Lạm c & 330 & 71,7 & 130 & 28,3 & & \\
\hline Không lạm dụng & 228 & 64,4 & 126 & 35,6 & וברם ח,/94 & 0,016 \\
\hline Tống & 558 & 68,6 & 256 & 31,4 & & \\
\hline
\end{tabular}

Nhận xét: Nam thanh niên lạm dụng rượu bia có sức khỏe kém cao hơn nhóm không lạm dụng rượu bia; tỷ lệ lần lượt là $71,7 \%$ và $64,4 \%$. Khác biệt có ý nghĩa thống kê với $p=0,016<0,05$.

\section{BÀN LUẬN \\ 4.1. Phân loại sức khỏe của đối tượng nghiên cứu}

4.1.1. Sức khỏe chung. Sức khỏe của nam thanh niên trong độ tuổi thực hiện NVQS tỉnh Cà Mau năm 2020 có tỷ lệ xếp theo thứ tự: Loại 6 cao nhất chiếm 33,9\%; loại 4 chiếm 20,9\%; loại 3 chiếm 20,1\%; loại 5 chiếm 13,8\%. Kết quả trên gần tương tự nghiên cứu của tác giả Nguyễn Hồng Tảo và Lê Vinh, tình trạng sức khỏe ở nam thanh niên đạt loại 4 cao nhất với $35,55 \%$, tiếp đến là loại 3 là $29,96 \%$ và thấp nhất là loại 1 là $0,93 \%$ [5]. Nghiên cứu của tác giả Phan Hải Đường, sức khỏe của thanh niên khám tuyển NVQS tại địa phương trên có tỷ lệ loại sức khỏe $1,2,3,4,5,6$ lần lượt là $0,9 \%$, $14,5 \%, 20,5 \%, 24,2 \%, 26,1 \%$ và $13,8 \%[6]$.

4.1.2. Phân loại thể lực tính theo chiêu cao, cân nặng và vòng ngực. Nam thanh niên trong độ tuổi thực hiện NVQS tại Cà Mau có thể lực loại 1 chiếm tỷ lệ cao nhất là $42,4 \%$, loại 2 và 3 lần lượt là $25,3 \%$ và $19,4 \%$; các nhóm còn lại chiếm tỷ lệ rất thấp.

Kết quả này tương đương với kết quả nghiên cứu của các tác giả Phan Hải Đường, thể lực loại
1 chiếm tỷ lệ cao nhất là $57,6 \%$ và loại 2 chiếm lệ 25,9\% [6]; tác giả Trương Trọng Lành, thể lực chung theo tuổi loại 1 là $58,47 \%$, loại 2 là 20,39\% [8]. Nghiên cứu của tác giả Lê Đức Thành tại tỉnh Đồng Nai năm 2010, thể lực đạt loại 1 , loại 2 chiếm tỷ lệ cao ở tất cả các lứa tuổi [7]. Nhìn chung, tình trạng thể lực của thanh niên thực hiện NVQS tại Cà Mau khá giống ở Đồng Nai. Tuy thanh niên trong độ tuổi thực hiện NVQS tại Cà Mau có sức khỏe tốt chiếm tỷ lệ thấp nhưng tình trạng thể lực của họ có loại tốt chiếm ưu thễ. Đầy là mục tiêu mong đợi trong chủ trương về phát triển tầm vóc con người Việt Nam mà Đảng và nhà nước đặc biệt quan tâm [1], [2].

4.1.3. Tỷ lệ các nhóm bệnh tật theo các chuyên khoa. Đối tượng thanh niên là lứa tuổi trẻ khỏe, kết quả trên có tỷ lệ không mắc bệnh nội khoa chiếm tỷ lệ thấp (nhóm 1 điểm 36,2\%), còn lại là có mắc bệnh tật nội khoa chiếm tỷ lệ cao 63,8\% (bao gồm nhóm 2, 3, 4, 5, 6 điểm, với tỷ lệ $17,6 \%, 19 \%, 9,7 \%, 6 \%, 11,4 \%)$. Kết quả của chúng tôi cao hơn nghiên cứu của Nay Phi La nghiên cứu ở đối tượng nam thanh niên thực hiện NVQS có tỷ lệ mắc bệnh nội khoa chiếm tỷ lệ 7,8\% trong số $25 \%$ có bệnh tật tức 
gần $2 \%$ so với tổng số đối tượng thuộc mẫu nghiên cứu. Cùng đối tượng trên, tại tỉnh Đắk Lắk, tác giả Nay Phi La nhận thây trong số các bệnh lý mà thanh niên khám tuyển NVQS năm 2011 mắc phải có $20 \%$ mắc bệnh lý tim mạch, $80 \%$ còn lại mắc các bệnh lý khác [4].

Tỷ lệ bệnh lý ngoại khoa ở thanh niên thực hiện NVQS tại Cà Mau là 13\% thấp hơn kết quả của Phan Hải Đường ở đối tượng thanh niên thực hiện NVQS tại huyện Nhơn Trạch tỉnh Đồng Nai năm 2014, tác giả trên ghi nhận có $15,4 \%$ đối tượng mắc bệnh ngoại khoa trong số các trường hợp có bệnh tật. Trong đó, bệnh đại trực tràng chiếm đa số $(43,1 \%)$, bệnh cơ xương khớp chiếm tỷ lệ thấp $(8,3 \%)$ [6].

4.3. Một số yếu tố liên quan đến sức khỏe kém của đối tượng nghiên cứu. Qua nghiên cứu, kết quả đề tài chúng tôi cho thấy nam thanh niên trong độ tuổi thực hiện NVQS có sức khỏe kém ở nhóm >20 tuổi cao 1,852 lần nhóm $\leq 20$ tuổi. Theo đó tuổi dưới 18 có sức khỏe tốt và rất tốt chiếm $83,3 \%, 64,2 \%$ cho người từ 18 - 64 tuổi và $44,8 \%$ cho người từ 65 tuổi trở lên [9]; trong Báo cáo quốc gia về thanh niên Việt Nam của Quỹ Dân số Liên hiệp quốc tại Việt Nam và Bộ Nội vụ thực hiện thì tình trạng thanh niên có sức khỏe yếu chiếm $1,8 \%$ ở độ tuổi từ $16-19$ và 2,2\% ở độ tuổi 20-24.

Về tình trạng sức khỏe kém với trình độ học vấn, kết quả đề tài chúng tôi tìm thấy có mối liên quan với tỷ lệ nam thanh niên sức khỏe kém thuộc nhóm trình độ THCS trở xuống chiếm $64,8 \%$ và THPT trở lển chiếm $70,7 \%$. Khác biệt có ý nghĩa thống kê với $p=0,046<0,05$.

Nam thanh niên trong độ tuổi thực hiện NVQS tại Cà Mau có sức khỏe kém ở nhóm sinh sống ở thành thị cao hơn nhóm sinh sống ở nông thôn; tỷ lệ lần lượt là $73,1 \%$ và $61,7 \%$. Khác biệt có ý nghĩa thống kê với $\mathrm{p}=$ $0,000<0,05$.

Nhóm lam dụng rượu bia có sức khỏe kém cao hơn nhóm không lạm dụng rượu bia; tỷ lệ lân lượt là $71,7 \%$ và $64,4 \%$. Khác biệt có ý nghĩa thống kê với $p=0,016<0,05$. Cùng đối tượng là thanh niên thực hiện NVQS ở huyện Nhơn Trạch tỉnh Đồng Nai, tác giả Phan Hải Đường [6] nhưng nhận thấy không có mối liên quan giữa tình trạng sức khỏe kém của đối tượng nghiên cứu với việc có và không uống rượu bia với tỷ lệ $66,2 \%$ và $59,4 \%$ với $p=0,28$.

\section{KẾT LUẬN}

Tỷ lệ các nhóm sức khỏe, thể lực và bênh tât: Tỷ lệ sức khỏe loại 1 chiếm 2,1\%, loại 2 chiểm
9,2\%, loại 3 chiếm 20,1\%, loại 4 chiếm 20,9\%, loại 5 chiếm 13,8\%, loại 6 chiếm 33,9\%. Nhóm sức khỏe tốt (loại 1,2,3) chiếm 31,4\%, nhóm sức khỏe kém (loại 4,5,6) chiếm 68,6\%). Tỷ lệ thể lực loại 1 chiếm 42,4\%, loại 2 chiếm 25,3\%, loại 3 chiếm 19,4\%, loại 4 chiếm 4,9\%, loại 5 chiếm 2,9\%, loại 6 chiếm $5 \%$; BMI $<18,5$ chiếm $22,6 \%$, từ 18,5 đến 24,9 chiếm $61,5 \%$, từ 25 đến 29,9 chiếm $11,8 \%$, từ 30 trở lên $4,1 \%$. Tỷ lê nam thanh niên không mắc bệnh nội khoa chiếm $36,2 \%$ và không mắc bệnh ngoại khoa chiếm $87 \%$. Một số yếu tố liên quan đến tình trạng thể lực và bệnh tật: Những đối tượng có tuổi trên 20 có tỷ lệ sức khỏe kém cao hơn $(\mathrm{OR}=1,852$, $\mathrm{p}=0,0001)$. Nam thanh niên có học vấn THCS có tỷ lệ sức khỏe kém thấp hớn $(O R=1,204$, $\mathrm{p}=0,046)$. Nam thanh niên có sức khỏe kém ở nhóm sinh sống ở thành thị cao hơn nhóm sinh sống ở nông thôn $(O R=0,704, p=0,000)$ và nhóm lạm dụng rượu bia tỷ lệ sức khỏe kém cao hơn $(O R=0,794, p=0,016)$.

\section{TÀI LIỆU THAM KHẢO}

1. Bô Quốc phòng (2015), Thông tư 140/2015/TT$B Q Q P$ ngày $16 / 12 / 2015$ vê $Q u y$ định tuyên chọn và goi công dân nhập ngũ

2. Bộ Y tế, Bố Quốc phòng (2016), Thông tứ liên tịch số $16 / 2016 /$ TTLT-BYT-BQP ngày $30 / 6 / 2016$ Quy định việc khám sức khỏe nghĩa vụ quân sự.

3. Phạm Văn Uýnh (1998), "Nghiển cứu thực traning thanh niên tỉnh Cà Mau, những giải pháp và chính sách cần thiết đối với thanh niên trước yệu cầu phát triển kinh tế xã hội", Đề tài nghiên cứu cấp tỉnh Cà Mau năm 1998.

4. Nay Phi La (2011), Nghiên cứu tình hình thể lực và bệnh tật của nam thanh niên khám tuyển nghĩa vụ quân sự tại thành phố Buôn Ma Thuột năm 2011, Luận án chuyên khoa cấp 2, Trường Đ̇ại học Y Dược Huế.

5. Nguyến Hồng Tảo, Lê Vinh (2006), Tình trạng thể lực và bệnh tật của thanh niên khám tuyển nghĩa vụ quân sự tại huyện Trảng Bom, tỉnh Đông Nai năm 2001 và 2006, Ỳ Học thành phố Hồ Chi Minh, 11, 1(2007), 154-159.

6. Phan Hái Đường (2014), "Nghiên cứu tình hình thể lực và sức khóe của nam thanh niên khám tuyển nghĩa vụ quân sự huyện Nhơn Trạch, tỉnh Đồng Nai năm 2013", Luâan án chuyên khoa cấp 2, Trương Đai học Y Dược Cần Thơ.

7. Lê Đức Thà̀nh (2011), "Nghiên cứu tình hình thể lực - sức khỏe của nam thanh niên ở lứa tuổi khám tuyển nghĩa vụ quân sự tại huyện Mỏ Cày, tỉnh Bến Tre năm 2007", Luận văn chuyên khoa cấp 1, Trường Đại học Y Dược Huế.

8. Trương Trọng Lành (2007), Nghiên cứu tình hình thể lực, bệnh tật của thanh niên ở lứa tuổi khám tuyến NVQQS huyện Đông Hòa tỉnh Phú Yên năm 2006, Luận văn chuyên khoa 1, Trường Đại học Y Dược Huế.

9. Unfpa và Bộ Nội vụ (2015), Báo cáo quốc gia về thanh niên Việt Nam, UnfpaViệt Nam, tr. 1-73. 